American Journal of Applied Sciences 6 (2): 263-267, 2009

ISSN 1546-9239

(C) 2009 Science Publications

\title{
Heuristic Algorithm with Simulation Model for Searching Optimal Reservoir Rule Curves
}

\author{
Anongrit Kangrang, Sudarat Compliew and Witsanukorn Chaiyapoom \\ Faculty of Engineering, Mahasarakham University, Khamriang Campus, \\ Kantharawichai, Mahasarakham, 44150, Thailand
}

\begin{abstract}
This study proposes a heuristic algorithm to connect with simulation model for searching the optimal reservoir rule curves. The proposed model was applied to determine the optimal rule curves of the Ubolratana reservoir (the Chi River Basin, Thailand). The results showed that the pattern of the obtained rule curves similar to the existing rule curve. Then the obtained rule curves were used to simulate the Ubolratana reservoir system with the synthetic inflows. The results indicated that the frequency of water shortage and the average water shortage are reduced to 44.31 and $43.75 \%$ respectively, the frequency of excess release and the average excess release are reduced to $24.08 \%$ and $22.81 \%$.
\end{abstract}

Key words: Reservoir operation, rule curves, heuristic algorithms, simulation model

\section{INTRODUCTION}

An integrated water resources management of demand and supply management is addressed in the possible practice and high efficiency. To manage the supply side, a reservoir simulation model is widely used to analyze the behavior of a system on the computer. Reservoir rule curves are fundamental guidelines for long term reservoir operation. Often, they are searched by reservoir simulation model and optimization techniques. Firstly, the rule curves are obtained from trial error of rule curves in reservoir simulation model $^{[1]}$. This method is straightforward and applicable for both simple and complex systems. However, the reservoir simulation method does not guarantee to yield the optimal rule curves because of the experienced person.

A Dynamic Programming (DP) is another optimization technique applied to search the non-linear problems of water resource ${ }^{[2-4]}$. Unfortunately, the application of DP to multi-reservoir system is limited due to a dimension problem. To overcome this problem Chleeraktrakoon and Kangrang ${ }^{[5]}$ applied the DP with a principle progressive optimality (DP-PPO) to determine the optimal rule curves. However, this technique is complicated application.

Last decade, Genetic Algorithms (GAs) has been applied to search optimal rule curves of the reservoir system $^{[6-9]}$. The best part of GAs is that they can handle any type of objective function. Furthermore, the proposed model can handle any condition of reservoir simulation such as initial reservoir capacity and the period of inflow record. The accepted objective functions are a shortage index, frequency of water shortage, average water shortage and magnitude of water deficit. However, the appropriate objective function for searching the curves is average water shortage. Also, a smoothing function constraint is required to include into the proposed GAs for fitting the rule curves ${ }^{[10]}$. However, GAs is complex to optimization technique because this method is complicacy for creating multi-computation to analysis the optimal reservoir rule curves.

A Heuristic Algorithm (HA) is an optimization technique which belongs to the family of local search. It is a relatively simple technique to implement, making it a popular first choice. The heuristic algorithm begins with one initial solution to the problem at hand, usually chosen at random. The string is then mutated and if the mutation results in higher fitness for the new solution than for the previous one, the new solution is kept, otherwise, the current solution is retained. The algorithm is then repeated until no mutation can be found that causes an increase in the current solution's fitness and this solution is returned as the result ${ }^{[11-13]}$.

This study proposes a heuristic algorithm to connect with simulation model for searching the optimal reservoir rule curves. A minimum average water shortage was used be the objective function for searching procedure. A smoothing function constraint is

Corresponding Author: Anongrit Kangrang, Faculty of Engineering, Mahasarakham University, Khamriang Campus, Kantharawichai, Mahasarakham, 44150, Thailand 
applied to fit the obtained rule curves. The proposed model was applied to determine the optimal rule curves of the Ubolratana reservoir (the Chi River Basin, Thailand).

\section{MATERIALS AND METHODS}

Simulation model: The developed simulation model in the previous study ${ }^{[10]}$ was adopted to modify in this study. This simulation model had been constructed on the concept of HEC- $3^{[14]}$ and it can be used to simulate the reservoir operation. The reservoir operating policies are based on the rule curves of individual reservoirs and the principles of water balance concept. The reservoir system operated along the standard operating policy as expressed in Eq. 1:

$$
\mathrm{R}_{v, \tau}=\left\{\begin{array}{l}
\mathrm{D}_{\tau}+\mathrm{W}_{v, \tau}-\mathrm{y}_{\tau}, \text { for } \mathrm{W}_{v, \tau} \geq \mathrm{y}_{\tau}+\mathrm{D}_{\tau} \\
\mathrm{D}_{\tau}, \text { for } \mathrm{x}_{\tau} \leq \mathrm{W}_{v, \tau}<\mathrm{y}_{\tau}+\mathrm{D}_{\tau} \\
\mathrm{D}_{\tau}+\mathrm{W}_{v, \tau}-\mathrm{x}_{\tau}, \text { for } \mathrm{x}_{\tau}-\mathrm{D}_{\tau} \leq \mathrm{W}_{v, \tau}<\mathrm{x}_{\tau} \\
0, \text { otherwise. }
\end{array}\right.
$$

which $R_{v, \tau}$ is the release discharges form the reservoir during year $v$ and period $\tau$ ( $\tau=1$ to 12 , representing January to December), $D_{\tau}$ is the water requirement of month $\tau, \mathrm{x}_{\tau}$ is lower rule curve of month $\tau, \mathrm{y}_{\tau}$ is upper rule curve of month $\tau$, and $\mathrm{W}_{v, \tau}$ is the available water calculated by simple water balance as described in Eq. 2:

$$
\mathrm{W}_{v, \tau+1}=\mathrm{S}_{v, \tau}+\mathrm{Q}_{v, \tau}-\mathrm{R}_{v, \tau}-\mathrm{E}_{\tau}-\mathrm{DS}
$$

where, $S_{v, \tau}$ is the stored water at the end of month $\tau$, $\mathrm{Q}_{v, \tau}$ is monthly reservoir inflow, $\mathrm{E}_{\tau}$ is average value of evaporation loss, and DS is the minimum reservoir storage capacity (the capacity of dead storage). In the Eq. 1, if available water is in a range of the upper and lower rule level, then demands are satisfied in full. If available water over the top of the upper rules level, then the water is spilled from the reservoir in downstream river in order to maintain water level at upper rule level. If available water is below the lower rule level, a reduction of supply is required. The policy usually reserves the available water $\left(\mathrm{W}_{v, \tau}\right)$ for reducing the risk of water shortage in the future, when $0 \leq \mathrm{W}_{v, \tau}<\mathrm{x}_{\tau}-\mathrm{D}_{\tau}$.

The results of reservoir simulation are the situations of water shortage and excess release water such as the number of failure year, the number of excess release water and the average annual shortage. They will be then recorded for using in developed HA.

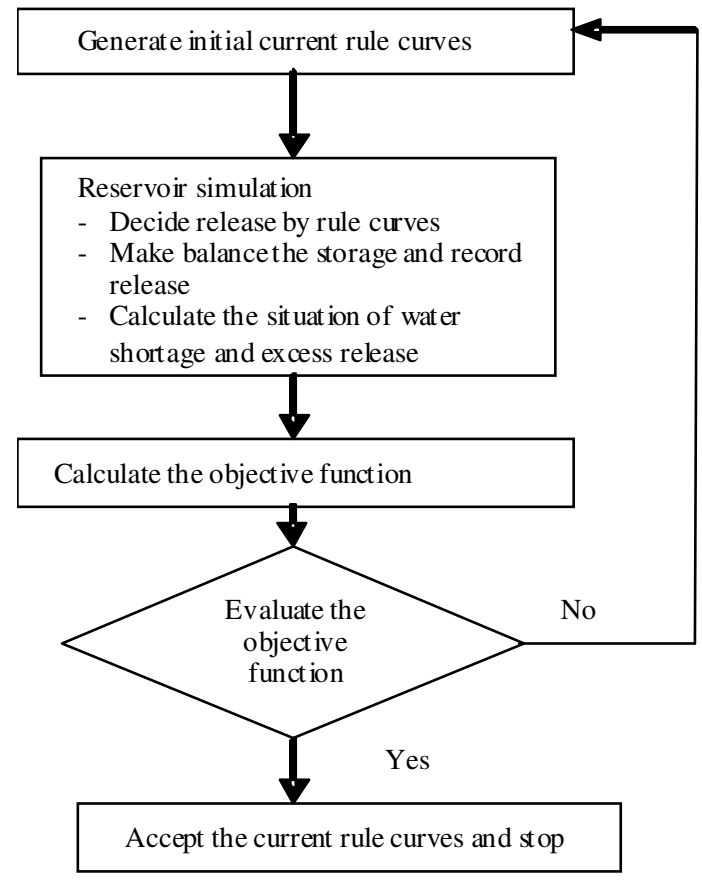

Fig. 1: Integration of heuristic algorithm and simulation model

Heuristic algorithm model: The heuristic algorithm begins with one initial solution to the problem at hand, usually chosen at random (lower rule curves and upper rule curve). Those initial solutions were used in the simulation model. Then, it was calculated water release in each months based on random rule curves for monitoring water storage as an objective function. For this study, the minimum average water shortage (MCM/year) was used as an objective function of searching rule curves as following.

$$
f(\mathrm{LRC}, \mathrm{UPRC})=\operatorname{Min}\left(\frac{1}{\mathrm{n}} \sum_{\mathrm{v}=1}^{\mathrm{n}} \mathrm{Sh}_{\mathrm{v}}\right)
$$

where, $\mathrm{n}$ is the total number of considered year. Shv is water deficit during year $v$. (year that release does not met $100 \%$ of target demand).

The assessment intervals of water shortage and excess release characteristics for new curves are simulation model comparison with the previous rule curves. If objective function of new curves less than theirs previous curves, this random rule curves is accepted. On the other hand, the new rule curves are generated based on the previous rule curves. The process will be stopped when the comparison between old objective function and current objective function does not difference (Fig. 1). 


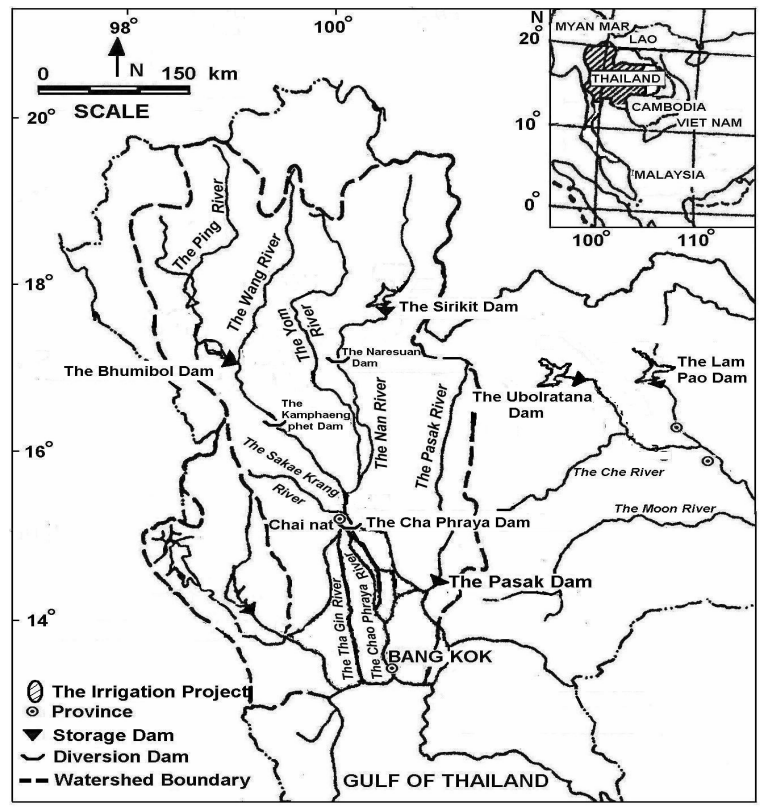

Fig. 2: Location of the ubolratana reservoirs

\section{ILLUSTRATIVE APPLICATION}

The developed model was applied to search the optimal rule curve of the Ubolratana Reservoir located in the northeast region of Thailand. Figure 2 shows the locations of the Bhumibol, Sirikit and Ubolratana Reservoirs.

As shown in Fig. 3, the schematic diagram of flows within the total drainage basin of the Ubolratana reservoir system. The Ubolratana Reservoir has the capacity of 2,263 MCM, the normal water level $182 \mathrm{~m}$ (MSL.) and the dead storage $410 \mathrm{MCM}$ at $174 \mathrm{~m}$ (MSL). The available water was released for electrical generator, water supply, industrial demand and irrigation demand (the Nong-Wei irrigation project). This project has agricultural area 41,504 hectares. The inflow records of station UBR (1958-2003) were considered. Furthermore, the other hydrological data for each month included series of evaporation losses and precipitation of the reservoirs and those of side flows were used for reservoir simulation.

The obtained rule curves were applied to the Monte Carlo simulation for evaluating the efficiency of the HA. The results were compared to the situations of water shortage and excess release (e.g., frequency, magnitude and duration). The Monte Carlo simulation study against 500 samples of generated monthly flows for stations $\mathrm{UBR}^{[15]}$ was used to compute the interval (mean \pm standard deviation) of the referred statistics for the assessment.

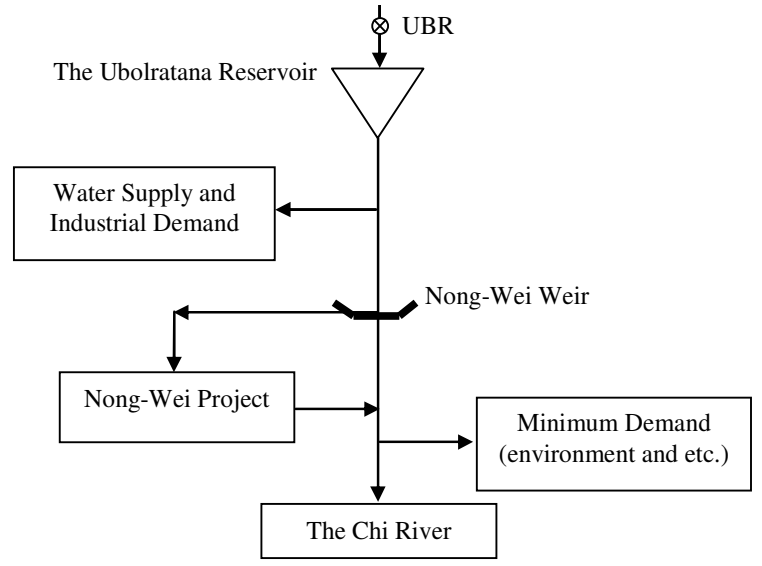

Fig. 3: Schematic diagram of flows in the Chi River Basin

In the following, the obtained assessment results of the considered water-deficit and excess-release properties for existing and HA cases were presented.

\section{RESULTS AND DISCUSSIONS}

Figure 4 shows the optimal rule curves of Heuristic Algorithm connected simulation with the smoothing function constraint. The pattern of the new rule curves is similar to the existing curves of the simulation. Then obtained rule curves were used to simulate the Ubolratana reservoir system. The monthly inflow were generated by SVD (MAR 1) ${ }^{[15]}$ for evaluating water shortage and flood frequency. The results are shown in Table 1. The results show the circumstances of water shortage and flood frequency (frequency of water shortage, average water shortage, the frequency of excess water and the average water release). The frequency of water shortage, the average water shortage and the maximum water shortage of rule curve's HA are $0.450 \pm 0.030$ time/years, $18 \pm 9 \mathrm{MCM} /$ year and $607 \pm 54 \mathrm{MCM} / \mathrm{year}$ respectively. The flood frequency of excess water release, the average excess water release and the maximum excess release of rule curve's HA are $0.640 \pm 0.063$ time/years, $917 \pm 143 \mathrm{MCM} /$ year and 3,332 $\pm 608 \mathrm{MCM} /$ year respectively. The results indicated that the frequency of water shortage and the average water shortage are reduced to 44.31 and $43.75 \%$ respectively, the frequency of excess release and the average excess release are reduced to 24.08 and $22.81 \%$ respectively. However, the average and maximum duration of water shortage and excess release in the both techniques are not different significantly. 
Am. J. Applied Sci., 6 (2): 263-267, 2009

Table 1: Frequency, magnitude and duration of water shortage for all inflow record types

\begin{tabular}{|c|c|c|c|c|c|c|c|}
\hline \multirow[b]{2}{*}{ Situations } & \multicolumn{2}{|c|}{ Rule curves } & \multirow{2}{*}{$\begin{array}{l}\text { Frequency } \\
\text { (times/ year) }\end{array}$} & \multicolumn{2}{|c|}{ Magnitude (MCM/year) } & \multicolumn{2}{|c|}{ Duration (year) } \\
\hline & & & & Average & Maximum & Average & Maximum \\
\hline \multirow[t]{4}{*}{ Water shortage } & Existing & $\mu$ & 0.808 & 32 & 204 & 2.2 & 3.7 \\
\hline & & $\sigma$ & 0.082 & 14 & 32 & 0.7 & 1.8 \\
\hline & HA & $\mu$ & 0.450 & 18 & 607 & 1.8 & 3.1 \\
\hline & & $\sigma$ & 0.030 & 9 & 54 & 0.7 & 1.4 \\
\hline \multirow[t]{4}{*}{ Excess release } & Existing & $\mu$ & 0.843 & 1,188 & 4,446 & 8.8 & 17.2 \\
\hline & & $\sigma$ & 0.073 & 194 & 1,825 & 5.6 & 7.0 \\
\hline & HA & $\mu$ & 0.640 & 917 & 3,332 & 9.2 & 17.4 \\
\hline & & $\sigma$ & 0.063 & 143 & 608 & 7.6 & 8.6 \\
\hline
\end{tabular}

$\mu=$ Mean; $\sigma=$ Standard deviation

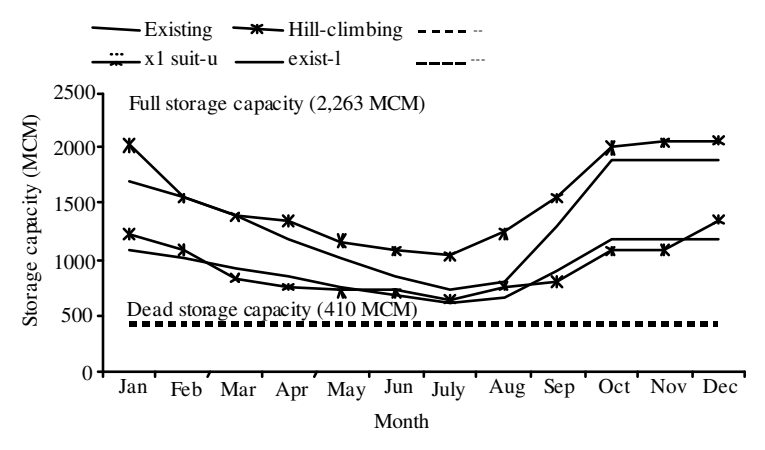

Fig. 4: Optimal rule curves of the Ubolratana Reservoir

\section{CONCLUSIONS}

Rule curves are necessary guides for long term reservoir operation. The optimization techniques applying to search the optimal rule curves include simulation model dynamic programming and genetic algorithm. This study proposed a heuristic algorithm connected simulation model to search the optimal rule curve. The smoothing-function constraint was used to fit rule curve. The proposed model was applied to determine the optimal rule curves of the Ubolratana reservoir (in the northeast region of Thailand). The results showed that the pattern of the obtained rule curves similar to the existing rule curve. Then the obtained rule curves were used to simulate the reservoir system. The results indicated that the frequency of water shortage and the average water shortage are reduced to 44.31 and $43.75 \%$ respectively, the frequency of excess release and the average excess release are reduced to 24.08 and $22.81 \%$ respectively. However, the average and maximum duration of water shortage and excess release in the both techniques are not different significantly.

\section{ACKNOWLEDGEMENT}

The authors would like to acknowledge the financial support by the faculty of Engineering,
Mahasarakham University. Thanks are also due to Dr. Alongkorn lamom and Mr. Somporn hongkong for helpful the development of model.

\section{REFERENCES}

1. Jain, S.K., M.K. Goel and P.K. Agarwal, 1998. Reservoir operation study of sabamati system, India. J. Water Resour. Plann. Manage., 124: 31-38.

2. Bellman, R., 1957a. Dynamic Programming. Princeton University Press, Princeton, New Jersey.

3. Yakowitz, S., 1982. Dynamic programming applications in water resource. Water Resour. Res., 18: 673-696.

4. Esogbue, A.O., 1989. Dynamic Programming for Optimal Water Resources Systems Analysis. Prentice Hall, Englewood Cliffs, New Jersey, pp: 435.

5. Chaleeraktrakoon, C. and A. Kangrang, 2007. Dynamic programming with the principle of progressive optimality for searching rule curves. Can. J. Civil Eng., 34: 170-176.

6. Chang, C.L. and C.C. Yang, 2002. Optimizing the rule curves for multi-reservoir operations using a genetic algorithm and HEC-5. J. Hydrosci. Hydraul. Eng., 20: 59-75.

7. Chang, J.F., S.J. Lai and S.L. Kao, 2003. Optimization of operation rule curves and flushing schedule in a reservoir. Hydrol. Processes, 17: 1623-1640.

8. Chen, L., 2003. Real coded genetic algorithm optimization of long term reservoir operation. J. Am. Water Resour. Assoc., 39: 1157-1165.

9. Chang, J.F., L. Chen and C.L. Chang, 2005. Optimizing reservoir operating rule curves by genetic algorithms. Hydrol. Processes, 19: 2277-2289.

10. Kangrang, A. and C. Chaleeraktrakoon, 2007. Genetic algorithms connected simulation with smoothing function for searching rule curves. Am. J. Applied Sci., 4: 73-79. 
11. Lamom, A., T. Thepchatri and W. Rivepiboon, 2008. Heuristic algorithm in optimal discrete structural designs. Am. J. Applied Sci., 5: 943-951.

12. Mantawy, A.H., S.A. Soliman and M.E. El-Hawary, 2003. An innovative simulated annealing approach to the long-term hydroscheduling problem. Int. J. Elect. Power Energy Syst., 25: 41-46.

13. Tospornsampan, J., I. Kita, M. Ishii and Y. Kitamura, 2005. Optimization of a multiple reservoir system operation using a combination of genetic algorithm and discrete differential dynamic programming: A case study in Mae Klong system, Thailand. Paddy Water Environ., 3: 29-38.
14. US Army Corps of Engineers, 1974. HEC-3 reservoir system analysis for conservation, user's manual. Hydrol.ogic Engineering Center, Davis, California, USA.

15. Chaleeraktrakoon, C., 1999. Stochastic procedure for generating seasonal flows. J. Hydrol. Eng., ASCE, 4: 337-343. 